\section{Why We Are OCEANOGRAPHERS}

\author{
By Henry Stommel
}

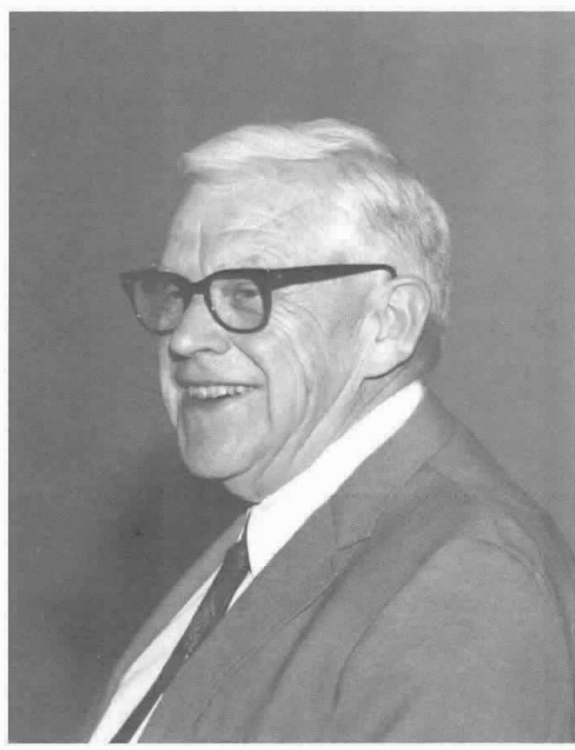

Henry Stommel

measure of the speed at which scientific knowledge has grown.

The numbers employed in science today quite probably exceed $90 \%$ of all the scientists that ever were in all human history. The proportion of living oceanographers to the all-time total is, I think, even larger than $90 \%$.

This expansion of job opportunities has its roots in the accelerated research effort during World War II. Many of my contemporaries-Andrew Bunker, Robert Reid, Don Pritchard, to mention but a few-came into oceanography because they had first been introduced to it in military meteorology training programs. The need for a per-

Henry Stommel, Woods Hole Oceanographic Institution. Woods Hole, MA 02543. manent post-war national effort in oceanography was first clearly enunciated by the National Academy of Sciences' Committee on Oceanography under the chairmanship of Harrison Brown in the mid-1950s. Over the years this Committee, under varying names and guises, and with varying effectiveness, established a rationale for expanded national funding as we now know it. The heyday of the Committee was, I think, during the years 1955-65-the time of the two-martini lunch - when its members included lobbyists from the pet-food and chemical industries, a retired investment banker well-acquainted with the Congress, and a sprinkling of charming promoters, as well as working scientists. Depending upon the shifting focus of public concern, the Committee espoused various causes: defense, food for the Third World, mining the ocean bottom, the Law of the Sea, preservation of the environment, and climate change. And Congress responded handsomely.

The success of the Committee also stimulated parallel efforts at promotion of oceanography in state governments, in international scientific unions, and in the United Nations Educational, Scientific and Cultural Organization (UNESCO). The universities responded by establishing new departments and schools of oceanography. And the ocean-cinematographer Jacques Cousteau made the general public aware of the sea in a compellingly romantic way, with an immediate appeal reminiscent of the narratives of the great ocean explorers of past centuries.

Oceanography was made visible to two generations of students. It offered a free graduate education. And so here we all are-recipients of the opportunities opened to us by a few resourceful promoters with a convincing brief. That is the first good hard reason that we became oceanographers, or rather, that we could become oceanogra- phers. The world has changed a lot since the day when Henry Bigelow advised Ray Montgomery not to enter oceanography because he did not have a private fortune. Those were the days when the Woods Hole Oceanographic Institution was known to its rivals from the Marine Biological Laboratory as the Harvard Yacht Club, and the Atlantis was encouraged to travel under sail because diesel fuel cost $\$ 15$ a day. So we really have a great deal to thank those promoters of 20-30 years ago for.

From the point of view of an individual faced with the decision of whether to enter upon a career in oceanography, the issues are more personal: will it be congenial, will it be interesting, does it suit my talents?

Certainly work at sea is congenial. It is a special social experience. Life on a small ship means living with people with backgrounds different from those of academia, and broadens our human contacts. Developing good instruments and getting good measurements at sea is challenging, and there are prospects of learning something new and unexpected. And there are foreign ports and remote islands to visit. For many, the regularity, the simplicity, of life at sea is therapeutic. Oceanographers like Nansen, who spent years living with others crowded in small ships in the Arctic, developed views of human relations that are different from those we learn on the freeway. George Deacon began his oceanographic career with four successive Antarctic cruises, each lasting eighteen months. The Discovery II became a home to him: a regular station schedule ( 8 in the morning and 8 at night), a good drink before dinner, and a game of pinochle in the bar before retiring. You'd learn the social arts quickly enough. Deacon was one of the kindest, gentlest and most persuasive men I have known. Work at sea rubs off the sharp edges, and makes us better people. The ship becomes a home away from home. That has changed a little 
for us at Woods Hole. now that our ships are "dry."

Oceanography is interesting because so much is still unknown and there is a great variety of activity - observational and theoretical-in which to submerge oneself. And if one tires of active research there are jobs at management level in which one can find important useful things to do.

Does it suit my talents? Those of us who entered oceanography from more highly developed sciences like astronomy. physical chemistry or physics have thought so. Thinking that we were unable to make much impact in these highly sophisticated fields, some of us found areas within oceanography where elcmentary ideas, simple theoretical models, first-order descriptions, and techniques borrowed from better-developed fields could be useful. I hope that it does not offend anyone when I suggest that oceanography has been attractive to many of us because it is low-powered. It's just a different way of saying that we preferred the pioneer homesteading model of the scientific life to the glitter of the intellectually lashionable.

On the whole we have done pretty well. A new field of geophysical fluid dynamics (a term coined by Willem Malkus about 1953 ) has grown, with deep connections to meteorology and astrophysics. Leaf through the 1942 treatise by Sverdrup, Johnson and Fleming and you are struck by the absence of any dynamical theory beyond Ekman's 1902 spiral and the elder Bjerknes 's practical method of doing dynamical current calculations. The most elementary problems had not been posed. nor the most primitive models constructed. Since then some of the vacuum has been filledenough anyway to fill textbooks and I fear give new students the impression that the vacuum has been completely filled. However. as students begin to think and work they will know better: they can still find an immense unexplored universe of ideas and phenomena to explore.

Many new sophisticated mathematical techniques that have increased our power to study the ocean have come from other disciplines. Fortunately there have been oceanographers with broad enough skills to translate these techniques into useful tools for oceanography. Singular perturbation theory and linear programming have come from applied mathematics. Most of the fundamental dynamical ideas. objective analysis and numerical modeling with data assimilation, have come from meteorology. Modern theory of time series analysis and techniques for detecting signals have come from electrical engineering. Inverse theory has come via geophysics. These transplants illustrate the benefits of getting a good education in something besides oceanography alone.

\section{$\mathrm{T}$} HE CHIEF SOURCE of ideas in oceanography comes. I think, from new observations. Today we take much of ocean knowledge for granted. There was a time when eddies and meanders were only dimly perceived (1948): a time when we didn't know of the existence of the equatorial undercurrent (1952), or that the slope of the isotherms in the Gulf Stream extends to the bottom (1954), or that there was a deep recirculation: a time when the deep western boundary currents of Greenland Sea water

\section{Whenit comes}

to the phenomenology

of the ocean, there are

more discoveries

than predictions.

had not been discovered flowing along the slope of Greenland around into the Labrador Sea (1952). There was a time when we didn't have reliable estimates of the flow through the Florida Straits (1960), when the ubiquity of inertial motions in the deep sea was not suspected (1957), when it could be thought that the velocity in deep water was too small to measure by current meter (1958). and when we had no clear observational description of a deep wintertime bottom-water formation event (1969).

More recently, we were surprised by multiple jets at the equator of the Indian Ocean (1976). by hot vents and the great helium plume in the Pacific, and by the red spectrum of the nine-year drift of Sound Fixing and Ranging (SOFAR) floats in the Atlantic. The geochemists persist in unsettling our mental equilibrium with new current patterns revealed by exotic tracers like freons. Who would have foreseen "meddies" (1981), and who knows their role in deep-sea mixing? There is the wonderful unfolding development of our knowledge about El Niño. There are those subtle features of the equation of state that Trevor McDougall has uncovered. And there is that amazing large-scale horizontal coher- ence of persistent doubly-diffusive layers revealed in the C-Salt (1987) expedition that is pregnant with implications concerning deep-ocean mixing processes.

I have mentioned only a few of the unexpected phenomena that have been discovered in the past few decades-merely the ones that come easily to mind. There seems to be no end of new surprises. And, if oceanographers are permitted in the future the freedom to follow their own noses, to scent out their own problems, and to formulate their own goals, this flow of new results will doubtless continue.

On the whole, when it comes to the phenomenology of the ocean, there are more discoveries than predictions. Most theories are about observations that have already been made. It is therefore particularly exciting when a theorist comes up with an idea about a feature of the ocean that he is willing to go to sea to look for. I urge those entering the field to take the risk.

So when we survey the personal reasons why we entered oceanography-that it be congenial, that it be suited to our talents, and that it be interesting - I think our choice of career was justified. And if some of us somehow can manage to avoid getting entangled in the "Big Science" part of our field, then perhaps we can preserve an innocent, simple approach to our tasks. Our work can seem like a pleasant hobby to us, it can sustain a sense of wonder, and bring us joy and fulfillment.

$T$ HERE IS A WONDERFUL story about the excellent Astronomer Royal George Airy that may serve as a warning of the perils of too much committee work and public service. Airy was very accomplished. He also was extremely fastidious; so much so that all his papers are preserved-every check book, account. letter. memo-even his scrap paper was sewed together and saved. He regularly updated an autobiography.

Airy is known to oceanographers as the author of an early tidal treatise and for the Airy function familiar to those who work with the equatorial beta-plane. He took on a huge amount of committee work. In 1845 (at the age of 43) he was president of the Royal Astronomical Society. He served on the Tidal Harbor Commission and did extensive studies of breakwaters at Dover Pier. He lectured on Irish tides and the design of saw mills. On the Standards Commission he contributed theoretical 
studies of the flexure of uniform bars: he helped determine the longitude of Valencia Island. Ircland; he visited tin mines. He oversaw the planning and execution of the survey of the international boundary between Maine and Quebec. He studied rotary engines. He made himself busy devising schemes for compensating magnetic compasses on iron-hulled ships. He served on the Railway Gauge Commission-whose purpose was to choose a British standard gauge-which, in his own words, he characterized as "an important employment."

Unfortunately he was so busy that he was not at home in September and October when the 24-year-old astronomer John C. Adams twice came down from Cambridge to visit him, in the hope of discussing his new prediction of the existence and location of a trans-Uranian planet - the one we now call Neptune. Adams had devised a way to work backward from the observed irregularities of the orbit of Uranus to the orbit of the disturbing planet. It was an early success of inverse theory. It was destined to become one of the most celebrated astronomical achievements.

Although they did not meet. Airy sent Adams a set of observations of Uranus that had been collected at Greenwich. Autumn turned to winter, and still Adams did not publish his work. Meanwhile. in Paris, independently, Leverrier had commenced his own attempt at explaining the irregularities of the Uranian orbit. By November 16, 1845, he had published his first results. and on June 2. 1846, the second part appeared. Airy corresponded with Leverrier. He was now aware that both predicted locations agreed to within a degree, and by July 16th Airy became somewhat alarmed for Adams " priority. Ten months had passed since Adams had tried to visit him, but still he did not urge Adams to publish. Instead he asked Challis at the Cambridge Observatory, where there was a new 12-inch refractor, to search for the new planet where Adams had indicated it to be. But Challis was preoccupied by his own comet program, and Airy, as he put it. "my nerves shaken by the work on the Railway Gauge Commission," traveled from August 10 to October 11 on the continent with his wife and her sister Elizabeth Smith to take the water at Wiesbaden and an excursion to the Swiss mountains. Meanwhile, on August
31 Leverrier's third paper was published. Airy then junketed to visit his friend Professor Hansen at Gotha, where he heard the astonishing news that on September 16th Leverrier had mailed his predicted location for the new planet to the Berlin Observatory. And within five days, Dr. Galle, using Bremiker's admirable map for Hora XXI as a reference, had observed the tiny eighthmagnitude disk of Neptune, with a retrograde motion in right ascension of six seconds a day. Praise and honors immediately showered upon Leverrier. Airy had a miserable five-day sea passage home from Hamburg to London (the crank-pin of the steamer broke and had to be repaired). And he was sea-sick.

\section{Breaking new ground \\ in science is such a difficult \\ process that it can only be done \\ by an individual mind.}

When he got home and put forward Adams claim. he was shouted down by both angry French and British: the French for sullying Leverrier's just claim to fame. and the British for being so inattentive to Adams" interests.

Breaking new ground in science is such a difficult process that it can only be done by an individual mind. For some of us, that is the main attraction of doing scientific work. In this respect it is like the art of painting or musical composition or poetry. The exhibitions, orchestral performances and public readings come later, as do the art dealers. the recording companies. and the paperback publishers. But it all begins with an individual's choice of medium, choice of theme and style and subject. And if you try to impose themes or goals with a social purpose you produce those grotesque travesties one sees in Peoples' Republics and commercial advertising.

Each of us has a finite supply of energy. We draw upon it when we think hard. supervise a technical group, or go to sea. Often it takes the last ounce of effort to break through to something new. So watch your Plimsoll mark, and don t become too heavily laden with other things to do. You need to be able to turn quickly. change plans, backtrack, and when the moment comes, to drop everything else to pursue that flighty elusive new clue.

\section{$T$} HE CREATIVE SCIENTIST asks the question that has not been posed before. $\mathrm{He}$ is like a perpetual graduate student in quest of a thesis topic. He discovers how to engage his own potential most effectively. Considerations of social relevance do not dominate his tactics. He embarks on a course as nearly orthogonal and independent of previously charted courses as he is capable of descrying. And with luck. the grace of the peer review system, and the support of the Science Foundation, he will produce some significantly new fact or thought. And it will bring joy.

The prospect of being an independent investigator is one of the great aturactions of oceanography, as contrasted to laboring within a preplanned program. Certainly there are drawbacks. You will be an employee, with a time-clock number. You will be employed by an impersonal corporation. owned by people you never see. They will monitor your performance, set your rank and salary, and decide whether you can stay on. They will not provide funds, however. for your research. Those you will have to seek, annually, by proposals to government funding agencies. The outcome will be decided by outside peer review. So you will be in double jeopardy.

But serving two separate masters is the key to the freedom you need to carve out your own research program. So if someone mentions block funding, or suggests a big project in which you are welcome to work. you might consider rolling over and playing dead.

You need not work entirely alone. From time to time you will find another investigator whose skills and equipment complement yours. This will be a collaboration for a single, well-defined scientific purpose, not collaboration for its own sake. It will be comfortably below the threshold of Big Science.

My own most pleasant past collaborations, with English. French and German 
oceanographers, were of this transient variety. Even the Mediterranean Deep Ocean Convection experiment (MEDOC-69), an international program involving six ships, lasted only three months and was organized completely in a single half-day meeting. The funding agencies were in different countries and so were all independent of one another, and we could work at the individual proposal level. In a sense the Genie of Big Planning was momentarily let out of the bottle...but it was easy to stuff back in again.

A few words about the Genie of Big Planning. It is an old acquaintance of scientists. When let out of the bottle it feeds on our attention and time. It requires constant attendance at its court. There are those who can look into its face without turning into pillars of salt. For others, like me, prolonged exposure threatens brain death.

In the early days of the Committee on Oceanography, when it came to putting some substance into a promotional report. one of the best and most effective statesmen of our science would commandeer the chalk and proceed to paraphrase the table of contents of Sverdrup's textbook as an outline. He repeated this performance over the years, just changing the words around a little. It provided an overall statement of the scope of oceanography at a time when few were acquainted with the word. It saved the rest of us a lot of work. It saw us through the 1950s. And it did not involve formulating detailed national plans. For the individual investigator, it did not threaten the integrity of the peer review system.

By 1958 , it became clear that we needed to augument the research fleet, and that launching something big would help justify the expense. The International Indian Ocean Expedition of the early 1960s was the adventitious child of this need. It was a last minute inspiration of Columbus Iselin's, who during a coffee break at an international meeting in Woods Hole happened to glance at a chart of the positions of deep hydrographic stations in the world ocean that was lying on the table in Fuglister's office. Iselin noticed the paucity of deep data in the Indian Ocean. A small idea expanded to fill a vacuum. He rejoined the meeting and suggested that an international expedition to the Indian Ocean might be the ticket. And soon we had the Atlantis $I I$ - the "new Discovery" - and had begun the last great nineteenth century cruises of geographical discovery. There was no master plan: each cruise was the work of an individual scientist. A significant data gap was filled. And it became possible to visit such features as the Somali Current. Our interest in the monsoonal circulations of the Indian Ocean date from that time. The Genie's bottle had been shaken, but the stopper was not loosened.

You will recall how. when as a school child, the geometry teacher had you stand in front of the class and asked you to prove an unfamiliar proposition of Euclid, and your mind went blank. You might have responded, "Should I drop a perpendicular,

\section{So watch your}

Plimsoll mark, and don't

become too heavily laden

with other things to do.

sir?" although you hadn t thought of the next step. Oceanographers, when confronted by a need for immediate action, respond by dropping a CTD and making a hydrographic section. It has been a fruitful reflex, often leading to important useful results.

If the West had too few ships, some science administrators in the Soviet Union were embarrassed by having too much ship time to justify. They acted reflexively. In 1962. they placed before UNESCO a proposal to ask its members to make regular quarterly hydrographic sections on a number of standard lines. If adopted, it would have soaked up much of the world's research-vessel time. Advocates argued on behalf of climate monitoring. We of the opposition feared that all our ships would be committed. The stopper in the bottle had been loosened, but before it popped out. a UNESCO delegation was sent to Moscow to offer a more scientifically interesting plan and ram the stopper hard home. The engineer of this countermove was a Russian. Konstantin Federov. Some major changes amongst the oceanographic and hydro-meteorological administrators in
Moscow followed, and a first rate scientist was appointed director of the Institute of Oceanography. Federov was a brave and skillful dragon-slayer. He was a good friend and an excellent marksman with a rifle.

Looking back to this time, one can now see how weak a sword that counterproposal was. It was technologically impossible in 1962 to set out and recover a field of 100 moorings, each with a string of reliable current meters. It was not exactly a matter of opposing the undesirable by the impossible, but more a matter of introducing a new language into the debate: the language of time series, aliasing. power spectra. separation of time and space scales. etc. - things those sturdy old polar explorer types who ran the Hydrometeorological Service didn 't know about.

Seven years went by: I gave up promoting mooring experiments. It was in 1969 that Andrei Monin so stung my pride that I got involved in the Mid-Ocean Dynamics Experiment (MODE). It was at a meeting in Dublin; Ozmidov gave a paper on a Russian current-meter mooring experiment. Monin and I were sitting at a white enamel table in the college cafeteria. In a mildly sardonic tone he asked, "Henry, what ever happened to the US 100-mooring experiment?"

By 1969. Sverdrup's table of contents was overtaken by the growth of oceanography, and a new technique had been developed to stimulate oceanography: The International Decade of Oceanography (IDOE). It became possible for the first time for oceanographers to organize sizable collaborative field projects and experiments. on a scale hitherto out of our reach. Under the wise leadership of Feenan Jennings it was possible to carry out MODE and the Geochemical Sections Program (GEOSECS). These projects involved important developments in measurement technology: for example. acquisition of significant numbers of moored current meters and SOFAR floats. The projects were a form of Big Science, but they were not permanently established. They were formed for a particular job and dissolved in a few years when that job was done. Some future historian reviewing science policy may decide that it was at this point that the Genie got out of the bottle. I don't think so. I hope not. But there was a steep increase in 
the amount of administrative work and committee meetings. At one time someone suggested that we manage our projects with "PERT" or organizational diagrams, something big industries were presumed to do. To comply. Allan Robinson and I actually hired an expert from the Sloane School of Management to do it for us. MODE and the less successful POLYMODE that followed exhausted four successive executive officers.

I really can't judge the full impact that these projects had on the field in the long run. In the short run. we got data available in no other way, we acquired numbers of new instruments, learned about objective analysis and. I think, did worthwhile science. MODE may have been a model for future process-oriented experiments. It was my first experience with the socio-adminstrative aspects of joint scientific planning with the funding agencies, and the setting of priorities that seemed to imply a preference for planned efforts over individual proposals. In the long run. one could reasonably be uneasy about whether this priority for the planned program was good for the future health of oceanography. I was certain that it stifled my own scientific productivity. And I realized that I wasn't shrewd enough to play poker with the professionals on the Potomac River Sidewheeler.

L

$\triangle O N G$ AGO at a meeting of the Harvard Oceanography Committee, the chairman announced that the committee had accumulated $\$ 30,000$ in funds of its own. and that the dean had asked to see him. He asked us for advice as to how to keep the dean from taking the money away. A distinguished chemistry professor said, "Remember that Dean Bundy is a lot smarter than you, and put all your cards on the table." I took that advice to heart.

It took a few years to find my way to the egress. In 1973, I chaired a National Academy of Sciences (NAS) report entitled "The Ocean "s Role in Climate Prediction" for something called the National Climate Plan. The meteorologists were embarking upon the First Global Atmospheric Research Program (GARP) and had invited us to join them. And, they had some funds to offer.

We had two meetings with at least 100 attendees. The substance of the rather slender report was a tabulation of assorted ongoing oceanographic projects, a time table, and some general remarks - not much of a report, really. It was something that one of us and a program officer could have produced over a weekend. Perhaps some of you will remember those hot September days in the parlor of the Brandigee Estate in Brookline, with the windows wide open.

\section{New ideas have}

a dynamics of their own;

they don't need

to be promoted.

We were sweating over the great central table, surrounded by fading opulence. and like Pharoah plagued by flying insects.

The atmosphere of the meeting was oppressive. As we pursued one tedious topic after another, the sense of having been there before and the enormity of what I was subjecting all my friends to overcame me. I went into some kind of emotional overdrive and spent the rest of the afternoon-with Claes Rooth-swatting flies. There was little joy in that meeting.

During the past decade, I have renounced the Genie and all its works and haven 't kept up with big planning. One does notice that there is a lot of coming and going over the surface of the earth - an unusually large number of meetings. The final World Ocean Circulation Experiment (WOCE) plan seems to be a fair balance between traditional and novel, between geographical and process-oriented programs. Participation in the planning has been widespread. Perhaps it really isn't Big Science at all-just an assemblage of the miscellaneous smaller projects that people would have wanted to do anyway. Surely there is a Dean Bundy who will see to it that the outsider, the little guy, doesn't get pushed off the edge of earth.

One is encouraged by the success of some of the other planned projects, such as Tropical Oceans-Global Atmosphere (TOGA). This is one instance where repeated standard Equatorial Pacific Ocean Current Study (EPOCS) sections made by National Oceanic and Atmospheric Administration (NOAA) vessels with the encouragement of Joe Fletcher have paid off in a handsome scientific fashion. This is a marvellous example of a natural system in which the sampling intervals and signal strengths are suitable for monitoring by standard sections. Further, the Office of Naval Research (ONR) still manifests its old high skill in identifying and assembling little groups of oceanographers to work fruitfully together on special process-oriented projects such as Topo and Subduction.

\section{Ifmy litTle STORY about Sir George} Airy has any prophetic value, and if our science is a healthy one, wonderful and unplanned things will happen, unrelated to the large scale planning. Young, unknown Leverriers will appear on the scene. They will be beginning post-docs unknown to our steering committees. And they will confound our cautious planning by important new insights that we had overlooked and by risking predictions that the rest of us will then be forced to confirm. New ideas have a dynamics of their own; they don't need to be promoted. If a simple theory can lead to a discovery in the real world, it commands attention, and is bound to shake up carefully planned programs.

Looking into the future beyond twenty years of WOCE, I think that we will see establishment of a regular oceanic data network, using remotely controlled vehicles to make routine subsurface measurements on a global scale, like that of the meteorological network. Presumably such regular data-collecting systems will eventually be taken over by responsible government agencies, and the research community will 
be relieved of taking much of these climatemotivated data. They will feed the hungry computers. But certainly we will always need ships to do our own work in the ocean.

Looking ahead. I think there may be a transformation in what we mean by "scientific understanding." When we use computers to process large amounts of data, it is a convenience that sharpens the data analysis. When we use complex numerical models to replace simple analytical ones, we may be doing something different. When we couple these numerical models to the inflow of data, in the so-called assimilation mode, we are doing something very different. And yet we must take this step if we are ever to have useful forecasting models for social purposes. Computers have also led us to accept the limits of predictability and have had a chastening effect on the arrogance of the exact sciences. Suppose that we concoct a model that actually forecasts climate with significant success. We know how the model is built because we programmed it. Once the program takes over it follows such intricate tortuous internal paths that we cannot understand them. It could be socially useful, maybe even a great triumph of sanitary engineering, but it will present us with a problem of understanding.

I wonder how our concept of understanding will evolve to accommodate itself to the complexity of these models. You all know that the notion of understanding is a rather slippery thing. For example. we can understand the interaction of discrete vortices most easily in terms of vorticity interactions, whereas resorting to the primitive inviscid equations would be a mess. We invoke ideas of normal modes in explaining vibrations. Rossby waves are easier to think of in terms of the vorticity equation rather than the momentum equations. These are old acquaintances: so, we are comfortable with them. To some extent analytical concepts will be recognizable in the first dataassimilating models. For example, in Moore and Anderson's recent assimilation of expendable bathythermograph (XBT) data into a layer model of the tropical Pacific Ocean (1989), the authors are able to interpret computed features as variants of familiar Kelvin and Rossby waves moving through the computed field and adjusting to the updated data. In more complicated models, features resembling analytically familiar ones may not dominate the action. and we will want new definitions of what we mean by understanding.

I have been asked by the three other surviving members of SOSO, the Society of Subprofessional Oceanographers, to convey our best wishes and felicitations to The Oceanography Society, and to wish it success. It will be an important forum in which oceanographers can consider their needs and can have an independent voice in or-

\section{All alone, one confronts the}

unknown and divines some meaning

from it. We sort the pieces and arrange them in new patterns.

ganizing their affairs. In the past we have derived great benefit from our association with other societies, but they inevitably had agenda additional to our own. Now we have a new start.

I hope that this is a good forum in which to make a statement of the main reason for being a scientist. as I see it. The president of the leading scientific honor society in this country has recently stated that students should be interested in science because it is fun. I think it is somewhat deeper than plain fun: it is a voyage of intellectual exploration. and an expression of the human spirit.

The conflicting tension between following one"s own sense of direction and dutifully serving a social purpose is a strong one. and especially when government funding is involved. I sense that so far I have given only one side of the story, so here are a few instances where the embattled pure scientist was unable to maintain a balance.

The history of science is strewn with melancholy wreckage from struggles to maintain some balance. When Furdinand Hassler was appointed first director of the Coast and Geodetic Survey in 1816, he tried to begin with a general triangulation grid along the eastern seaboard. It was slow, meticulous work, and to many congressmen it seemed much too academic. He was insensitive to the impatient commercial interests who wanted immediate surveys of their harbors. Consequently the survey was disbanded in 1819. Thirteen years later it was resurrected under the superintendency of the more worldly Alexander Dallas Bache. Under Bache, the Coast Survey made many fine charts and maintained high professional standards. It even served as a refuge for a few scientists.

Joseph Henry had great hopes that the Smithsonian Institution would be a national center for pure science. He was frustrated by the federal government "s differing view: that it was the nation's attic.

There is the case of Josiah Whitney (for whom the mountain is named) who in 1861 was appointed head of the Geological Survey of California, on Louis Agassiz's recommendation. He embarked upon a serious scientific survey and had to appear before the state legislature each year to ask for a continuing appropriation. This was a time scarcely eleven years after the gold rush, and the lawmakers were anxious to exploit mineral resources. Whitney fed them a diet of paleontology, and undiplomatically lectured them on merits of science for its own sake and the evils of crass commercialism. The survey was discontinued after four years. Whitney was so outraged that he lost his sense of equilibrium and began to behave in a demented fashion; he lashed out against innocent bystanders, accused his colleagues of improprieties, and tried to destroy the reputation of his old acquaintance Benjamin Silliman, Jr. of Yale because Silliman had publicized the opinion that there were useful oil reserves in Southern California. Whitney was on record that there were none.

In the nineteenth century, American scientists were very much on the defensive against the popularity of the unschooled Yankee inventor. Thomas Edison established the first industrial laboratory in 1872 . By 1876, he demonstrated his phonograph and carbon microphone before the National Academy of Sciences, but it was not im- 
pressed. Edison went on to invent the electric light. the motion picture camera-and founded whole industries. During World War I, the Navy had to consult him outside the National Research Council. Edison liked to make fun of pure scientists and loved to play the role of the common-sense practical engineer. In 1926, efforts were made belatedly to elect him to the engineering section of the Academy.

The members of long-standing who had resolutely opposed his election for fifty years had mostly passed away. R.A. Millikan made an impassioned speech of nomination, in which he asked, "Is there any physicist here who will deny that Edison has made great contributions to science?" and A.A. Michelson rose from his seat to say, "I am that physicist." He was the President of the Academy. This is a measure of how much pure scientists sometimes feel on the defensive.

With growing appreciation of approaching ecological disaster, oceanography has now been swept up in the effort to stave it off. There are important jobs to be doneand perhaps scientists like Hassler, Henry, Whitney, and Michelson would not be psychologically equipped to implement them. Perhaps oceanography has come of age in this respect. and in the future will inevitably be increasingly organized. So you see - in all honesty-there is another side to the question of pure science and scientific planning for public service. I'm trying to give the Genie his due, and to clarify the nature of the tension between the two sides. This new Oceanography Society can serve both pure and applied, the little and the big, the individual and the programmed.

However. in my heart I believe that, for a scientist, it is his personal mental wrestling match with some aspect of the universe that is his central activity and reward. All alone, one confronts the unknown and divines some meaning from it. We sort the pieces and arrange them in new patterns.

When we stand before the tomb of Isaac Newton in Westminster Abbey, our sense of reverence stems not from his eminence as President of the Royal Society, or because as Master of the Mint he was so good at catching counterfeiters.

We worship his memory because of that golden year in 1666 when as a youth. exiled to the Lincolnshire countryside on account of the plague in Cambridge, he laid down, with the help of his own home-made calculus, the principles of theoretical mechanics. His overweening sense of self-importance and his government service came afterwards.

We have recently celebrated the twentieth anniversary of NASA's Apollo Mission, one of the largest and most expensive planned technological feats of all timeyet I think it no exaggeration to assert that, in a basic sense. it actually was the blazing fire in the mind of the boy Newton that put those men on the moon.

Members of the Society. we are putting the fate of oceanography into your hands. We trust you will be faithful keepers of that flame.

\section{The Oceanography Society’s Logo}

\author{
By David A. Brooks
}

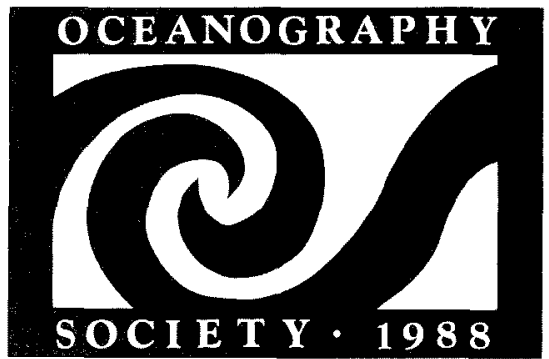

the Minoan culture--people in love with the natural world. The world they described in their art was whole and clearly interdependent. Natural forms were thoroughly integrated in the most utilitarian creations. Imagination was given respect. What I perceived at the root of all their work-and play-was an abiding awareness of and respect for the natural world and man's and woman's part in it. A kind of humility. And a sense of wonder.

When I heard about the logo contest I immediately thought of the sea and the sky and of how the Minoans had depicted it again and again- spirals spiralling into other spirals, an endless interplay. I thought of forces acting upon other forces, and yet a wholeness and harmony throughout.

\section{Biographical Sketches}

Kathy Madison entered the field of design after taking degrees in philosophy, literature and history from the University of Minnesota. She is building a small company devoted to creating imaginative designs for a wide group of clients, ranging from non-profit social service agencies to recruitment firms to a very special electronic mail company. She paints and writes in her free time. She lives in Brookline, Massachusetts, with her ten-year-old son.

Jill McKay, born in England and raised in Africa, has lived in the United States for ten years. She has been working at Omnet for nearly five years. She got to know Kathy when they worked together on the parents board of their sons after-school daycare program. She persuaded Kathy to draw cartoons for the Omnet newsletter, and later to design Omnet's Plain English Manual. When the logo competition was announced, Kathy seemed a natural. $\square$ 